\title{
INDEX COPIOSUS
}

\author{
AD K. LACHMANNI
}

\section{COMMENTARIUM IN T. LUCRETII CARI}

DE RERUM NATURA LIBROS

CONFECIT

FRANCISCUS HARDER

\section{BEROLINI}

TYPIS ET IMPENSIS G. REIMERI

MDCCCLXXXII 
